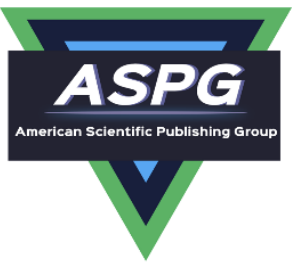

\title{
Handling within-word and cross-word pronunciation variation for Arabic speech recognition (knowledge-based approach)
}

\author{
Ibrahim El-Henawy, Marwa Abo-Elazm* \\ Computer Science Department Faculty of Computers and Informatics Zagazig University Egypt \\ Emails: henawy2000@yahoo.com, marwa_abdella@yahoo.com
}

\begin{abstract}
Arabic is one of the phonetically complex languages, and the creation of accurate speech recognition system is a challengeable task. Phonetic dictionary is essential component in automatic speech recognition system (ASR). The pronunciation variations in Arabic are tangible and are investigated widely using data driven approach or knowledge based approach. The phonological rules are used to get the pronunciation of each word accurately to reduce the mismatch between the actual phoneme representation of the spoken words and ASR dictionary. Several studies in Arabic ASR system are conducted using different number of phonological rules. In this paper we focus on those rule that handle within-word pronunciation variation and cross-word pronunciation variation. The experimental results indicate that handling within-word pronunciation variation using phonological rule doesn't enhance the recognition performance, but using these rules to handle cross-word variation provide a good performance.
\end{abstract}

Keywords: Speech Recognition Systems; Arabic Language; Phonetic Dictionary; pronunciation variations

\section{Introduction}

Automatic speech recognition can be defined as converting the speech signal into text. The quality of the system is measure by known how much the recognized text is close to the text recognized by human. Speech recognition is take a large interest in many fields such as the natural language processing (NLP) and human computer interaction (HCI). There are three types of Arabic language each has different characteristic [1]: Classical Arabic (CA), that is the formal and standard form of Arabic, it is the Quran language, Modern Standard Arabic (MSA), used in TV and the news the "common language" used by speakers of different dialects, and Spoken Arabic (dialect), that differ from one country to other and have no organized writing form. Despite the importance of Arabic language and the research effort, Arabic Automatic Speech Recognition (ASR) is unfortunately still insufficient. Several issues for Arabic language that need to be addressed to catch up with the progress of other language [2]. Dicritization is one of obstacle face Arabic ASR systems, science not all text is dicritized and this lead to shortage in the training data needed by ASR systems. Dicritization is essential for Arabic ASR system that is integrated with other system in which this system perform better using diacritics such as speech-to-speech systems[3] .The other problem is morphological complexity since Arabic has a large potential of word forms that increases the out-vocabulary rate. Also pronunciation variations (within word or cross word variation) lead to mismatch between the spoken word and the text used in the ARS system modelling. Within-word variation causes alternate pronunciations to the same word. In contrast, a cross-word variation happens in continuous speech in which a sequence of words forms a compound word that must be treated as one entity [4]. Modelling the pronunciation variation in any ASR system is a critical task. It helps to improve the performance by reducing the mismatch between the speech and the text used in the acoustic model training [5-6]. 
Two main methods used in the previous literature in modelling the pronunciation -variation [7-8] Knowledge-based approach, that uses phonetic and linguistic knowledge to write phonological rules that handle variants in pronunciation. Data-driven approach uses a corpus from real speech to derive the variation in speech. The chosen approach depends on the type of variation you need to handle in your work and the purpose of handling these variations [6]. The pronunciation variation modelling should be considered in three levels: the pronunciation dictionary, acoustic model, and the language model [9].

\section{Arabic phoneme set}

The phoneme is the small and basic unit of speech. It represents a distinct sound of the language's phonology. Any phoneme change in a word makes a change in the meaning of the word. Phonemes play a vital role in the performance of ASR and text to speech systems. In this work, we used a phoneme set that is used in [10] in addition to the proposed phoneme to generate the adapted dictionary to handle within word variation. Arabic language contain 28 consonant, 3 short vowels represent Fatha, Damma, and Kasra,3 long vowels that are the long version of the short vowels and the pharyngealized allophone as illustrated in table 1.

Table 1. The phoneme set used in training

\begin{tabular}{|c|c|c|c|c|c|c|c|}
\hline Number & $\begin{array}{l}\text { Arabic } \\
\text { phonem } \\
\text { e }\end{array}$ & $\begin{array}{l}\text { Romani } \\
\text { zed } \\
\text { phonem } \\
\text { e }\end{array}$ & Description & Number & $\begin{array}{l}\text { Arabic } \\
\text { phoneme }\end{array}$ & $\begin{array}{l}\text { Roma } \\
\text { nized } \\
\text { phone } \\
\text { me }\end{array}$ & Description \\
\hline 1 & - & /AE/ & diacritical marks FATHA & 24 & $\dot{j}$ & /DH/ & $\begin{array}{l}\text { Arabic consonant } \\
\text { ZAL }\end{array}$ \\
\hline 2 & i & /AE:/ & long vowel of $\mathrm{AE}$ & 25 & J & $/ \mathrm{R} /$ & $\begin{array}{ll}\text { Arabic consonant } \\
\text { RA }\end{array}$ \\
\hline 3 & - & /AA/ & $\begin{array}{l}\text { the pharyngealizd } \\
\text { allophone of /AE/ }\end{array}$ & 26 & j & /Z/ & $\begin{array}{ll}\text { Arabic } & \text { consonant } \\
\text { ZA } & \end{array}$ \\
\hline 4 & - & /AA:/ & Long version of AA & 27 & 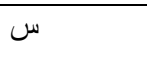 & $/ \mathrm{S} /$ & $\begin{array}{ll}\text { Arabic consonant } \\
\text { SEEN }\end{array}$ \\
\hline 5 & - & /AH/ & Emphatic Version of /AE/ & 28 & ش & /SH/ & $\begin{array}{ll}\text { Arabic consonant } \\
\text { SHEEN }\end{array}$ \\
\hline 6 & - & /AH:/ & Long version of $\mathrm{AH}$ & 29 & 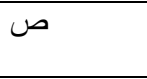 & /SS/ & $\begin{array}{ll}\text { Arabic } & \text { consonant } \\
\text { SAD } & \\
\end{array}$ \\
\hline 7 & - & /UH/ & $\begin{array}{ll}\text { Diacritical marks } \\
\text { DHAMMA }\end{array}$ & 30 & 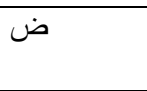 & /DD/ & $\begin{array}{ll}\text { Arabic } & \text { consonant } \\
\text { DAD } & \\
\end{array}$ \\
\hline 8 & وُ & /UW/ & Long vowel UH & 31 & b & TT & $\begin{array}{ll}\text { Arabic consonant } \\
\text { TA }\end{array}$ \\
\hline 9 & - & /UX/ & $\begin{array}{l}\text { the pharyngealized } \\
\text { allophone of /UH/ }\end{array}$ & 32 & ظ & $\mathrm{DH} 2$ & $\begin{array}{ll}\text { Arabic consonant } \\
\text { THA }\end{array}$ \\
\hline 10 & $*$ & $/ \mathrm{IH} /$ & $\begin{array}{ll}\text { diacritical marks } \\
\text { KASSRA }\end{array}$ & 33 & $\varepsilon$ & AI & $\begin{array}{ll}\text { Arabic } & \text { consonant } \\
\text { AIN } & \\
\end{array}$ \\
\hline 11 & ي & /IY/ & Long vowel of IY & 34 & $\dot{\varepsilon}$ & $\begin{array}{l}\mathrm{G} \\
\mathrm{H}\end{array}$ & $\begin{array}{ll}\text { Arabic } & \text { consonant } \\
\text { GHAIN } & \end{array}$ \\
\hline 12 & $*$ & /IX/ & $\begin{array}{l}\text { the pharyngealizd } \\
\text { allophone of /IH/ }\end{array}$ & 35 & ف & $\mathrm{F}$ & $\begin{array}{ll}\text { Arabic consonant } \\
\text { FA }\end{array}$ \\
\hline 13 & $*$ & /IX:/ & Long version of IX & 36 & ق & Q & $\begin{array}{ll}\text { Arabic } & \text { consonant } \\
\text { QAF } & \\
\end{array}$ \\
\hline 14 & وَ & /AW/ & $\begin{array}{l}\text { A Diphthong of both /AE/ } \\
\text { and /UH/ }\end{array}$ & 37 & ك & $\mathrm{K}$ & $\begin{array}{ll}\text { Arabic } & \text { consonant } \\
\text { KAF } & \end{array}$ \\
\hline 15 & ⿶ & /AY/ & $\begin{array}{l}\text { A Diphthong of both /AE/ } \\
\text { and /IH/ }\end{array}$ & 38 & J & $\mathrm{L}$ & $\begin{array}{ll}\text { Arabic consonant } \\
\text { LAM }\end{array}$ \\
\hline 16 & 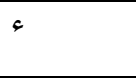 & $/ \mathrm{E} /$ & Hamza & 39 & s & M & $\begin{array}{ll}\text { Arabic } & \text { consonant } \\
\text { MEM } & \\
\end{array}$ \\
\hline
\end{tabular}




\begin{tabular}{|c|c|c|c|c|c|c|c|}
\hline 17 & ب ب & /B/ & Arabic consonant BA & 40 & ن ن & $\mathrm{N}$ & $\begin{array}{ll}\text { Arabic } & \text { consonant } \\
\text { NON } & \\
\end{array}$ \\
\hline 18 & ت & $/ \mathrm{T} /$ & Arabic consonant TA & 41 & ن ن & $\mathrm{NN}$ & $\begin{array}{ll}\text { Arabic } & \text { consonant } \\
\text { NON } & \end{array}$ \\
\hline 19 & ث & /TH/ & Arabic consonant THA & 42 & ن & NK & $\begin{array}{ll}\text { Arabic } & \text { consonant } \\
\text { NON } & \end{array}$ \\
\hline 20 & ج & $/ \mathrm{JH} /$ & Arabic consonant GEEM & 43 & ن ن & $\mathrm{NF}$ & $\begin{array}{ll}\text { Arabic } & \text { consonant } \\
\text { NON } & \end{array}$ \\
\hline 21 & $\tau$ & /HH/ & Arabic consonant HA & 44 & 。 & $\mathrm{H}$ & $\begin{array}{l}\text { Arabic consonant } \\
\text { HA }\end{array}$ \\
\hline 22 & $\dot{\tau}$ & $/ \mathrm{KH} /$ & Arabic consonant KHA & 45 & 9 & $\mathrm{~W}$ & $\begin{array}{ll}\text { Arabic Semi-vowel } \\
\text { WAW }\end{array}$ \\
\hline 23 & 2 & /D/ & Arabic consonant DAL & 46 & s & $\mathrm{Y}$ & $\begin{array}{l}\text { Arabic Semi-vowel } \\
\text { YA }\end{array}$ \\
\hline
\end{tabular}

\section{The Arabic phonological rules}

The phonetic dictionary has a great impact on the accuracy of ASR system, it contains the words available in the language and their pronunciation as a phonemes or allophones exist in the acoustic model. the dictionary creation can be done manually by expert but it's a hard task and take a big time for example English dictionary is built manually over many years because of large exceptions [10]. The pronunciation of Arabic language follow a specific rules especially when the text is fully diacritized, so the creation of the phonetic dictionary can be done automatically following this rules [11-12]. After the dictionary generation it can be adapted manually for exception words. a number of research issues for Arabic speech recognition such as absence of short vowels in written text and the presence of compound words generated from the concatenation of conjunctions, prepositions, articles, and pronouns, as prefixes and suffixes to the word stem is discussed in[13].An Arabic broadcast news transcription system is developed and its phonetic dictionary provides different pronunciation variations for words that may be pronounced differently[14]. A change to the standard phonetic rule to adapt the pronunciation variation for better training and decoding process is developed. A rule-based technique is developed to generate Arabic phonetic dictionaries for a large vocabulary speech recognition system [10]. They used classic Arabic pronunciation rules, MSA rules, and morphologically driven rules. Al-Haj et al. (2009) create a knowledge based approach to handle short vowels for Iraqi-Arabic speech and a number of pronunciation variations to the phonetic dictionary. A set of 80 pronunciation rules is generated to create a phonetic dictionary for the Tunisian Arabic [15].

\section{The proposed method}

Some of letters have different pronunciation when followed by a special letter such as letter DAL[d], THE[t] and $\mathrm{DAD}[\mathrm{dd}]$ for example the letter DAL( $(د)$ when followed by a voweled TEH(ت) it is omitted also, the letter DAD (ض) when followed by a voweled TEH(ت) or TAH(b) is omitted [2], but Ramsay et al. (2014) made modifications to this rules in which the letter DAL(د) is pronounced as $[\mathrm{t}]$ when followed by a voweled $\operatorname{TEH}(ت)$ also, letter $\mathrm{TEH}(ت)$ is pronounced as [d] when followed by letter DAL(د). Ali et.al (2009) indicates that the consonant noon(ن)is partially assimilated into meem(ק) when followed by baa(ب) For example the word (ن E N B A R) is pronounced [M E M B A R] , but Ramsay et .al (2014)add another rule for the letter noon (ن) see figure 1. 
NOON:

$$
\begin{aligned}
& .(?=\mathrm{BEH})->\mathrm{M} \\
& .(?=\mathrm{FEH})->\mathrm{m} \\
& (?=(\mathrm{QAF} \mid \mathrm{KAF}))->\mathrm{y} \\
& .(?=\mathrm{PN})->\mathrm{n}
\end{aligned}
$$

Figure(1) NOON assimilations rule

It indicate that this letter adopts the labiality of the consonant FEH [f] and is assimilated to [m] every time it is followed by FEH [f] For example the word يَف (Y A N F A Z) is pronounced[Y A m F A Z], also it adopts the verity of the sounds KAF $[\mathrm{k}]$ and QAF $[\mathrm{q}]$ when followed by one of them and is pronounced as $[\mathrm{g}]$. For example the word بَ (B A N K) is pronounced [B A n K]. it is assimilated to the palatal nasal consonant [ $\mathrm{n}$ ] when followed by one of the sounds articulated from the postal veolar points and dental, both stops and fricatives(PN), namely: DAD(ض), TAH(ط), ZAH(ظ), ZAIN(j), SEEN(w), SHEEN(ش), JEEM(ج), THEH(ث),THE(ت),THAL(ذ), DAL(د), ZAIN(j). For example the word (M A A N TH O R A) is pronounced [M A n TH O R A]. Table2 shows the

\begin{tabular}{|c|c|c|c|}
\hline Rule & example & Point view1 & Point view2 \\
\hline DAD asmiliation & أَفَضْتُم & E AE F AE DD T UH M & E AE F AE T UH M \\
\hline DAL asmiliation & عُدتُ & AI UH T T UH & AI UH T UH \\
\hline Shadda & العِرقِيُ & E L AI IH R Q IX Y Y UH & E L AI IH R Q IX Y UH \\
\hline \multirow{3}{*}{$\begin{array}{l}\text { Noon } \\
\text { Asmiliation }\end{array}$} & إنستَانٍ & E IH NN S AE: N & E IH N S AE: N \\
\hline & العَكَبُوتِ & E L AI AE NK K AE B UW T IH & $\begin{array}{l}\text { E L AI AE N K AE B UW T } \\
\text { IH }\end{array}$ \\
\hline & العُنِ & E L AI UH NF F IH & E L AI UH N F IH \\
\hline
\end{tabular}
phonetic dictionary for the two approaches in which point view 1 for the approach in [5] and point view 2 for the approach in [2]. The phoneme NN, NK and NF are used to represent ${ }_{+}, y$ and $m$ respectively.

Table 2 Arabic phonological rules

Ramsy et al. (2014) investigate the noon nasalation rule with another rule such as Shadda(الثدة)and tanween(التنوين) on a small corpora 20 sentence, indicating that the total performance is enhanced, but Al-Anzi Fawaz et al (2017) investigate the Shadda(الثندة) (التنوين) separately indicating that employed phonological rules are of no significant performance enhancement

The proposed method generate the dictionary adaption using the phonological rules used in Ramsy et al. (2014) duplicate the letter with shadda for example $\stackrel{\mu}{\text { become }} \mathrm{b} b$ and the assimilation of N TO NN ,NF or NK.

\section{Experiment result}

This experiment is conducted using Nawar Halabi dataset that is continuous speaker dependent speech corpus. The transcript of the dataset was collected from Aljazeera Learn (Al Jazeera, 2015), which is a language learning website 
that was chosen because it contained fully discretised text which makes it easier to phonetise. The training data consist of 1813 files about 3.8h. The test data consist of 100 files about 18 minutes. Carnegie Mellon University (CMU) sphinx 3 ASR engine is used. The WAV files are resampled to match the engine requirements i.e. sampling rate is $16 \mathrm{kHz}, 16$ bits and Wave format is Mono wav. The engine uses 3 state Hidden Markove Model. All wav file is fully transcribed in full dicritized text. A transcript file tells the trainer which unit sounds it should learn the parameters of, and at least their order in every speech signal in the training. It contain a series of words and nonspeech sounds are written according to their order in a speech signal, followed by a tag to join this order with the corresponding speech signal. The base line system used in this experiment is the system provided by Ali et al. (2009).The acoustic model is trained using sphinxtrain continuous dependent (CD) Hidden Markove Model. The performance of the model is affected by the number of densities, so the experiment is repeated for 8, 16, 32 and 64 densities, the smallest WER is $11.27 \%$ achieved using 16 density see figure 2 . Two experiments are conducted using the number of densities that has the small WER to verify the two rules: the nasalation of noon (ن) and Shadda (الثدة) rule. The two -experiment show that no enhancement is done with these rule: duplicating phoneme that proceed shadda and this is the same result obtained by Al-Anzi Fawaz et al (2017), also noon assimilation doesn't enhance the performance of ASR system see table 4 .

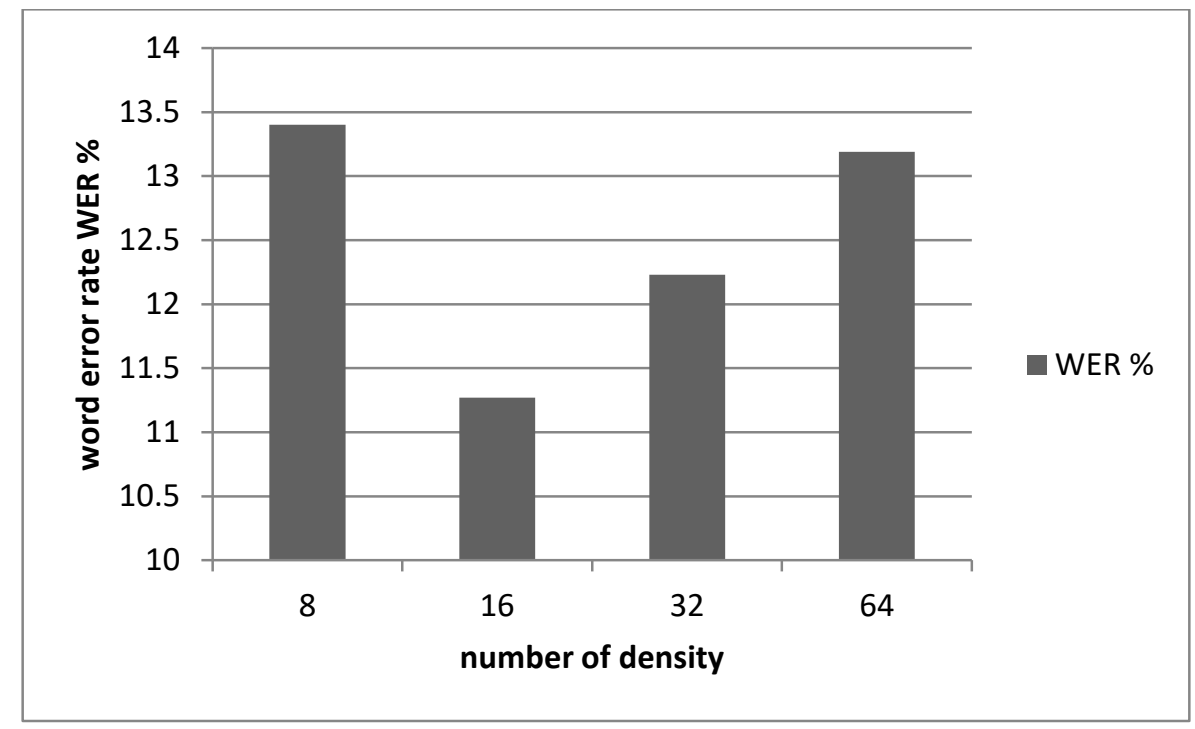

Figure(2) the word error rate (WER) for different number of density

\section{Handling Cross-word pronunciation variations}

Cross-word pronunciation variations change the phonetic spelling of words outside their listed forms in the phonetic dictionary, this lead to a number of Out-Of-Vocabulary (OOV) word forms [8]. The cross-word variation occurs at the intervals of words that is captured by the triphones of the acoustic model. It could also be realized as a change in pronunciation according to the last phoneme of a word and the first phoneme of the next word [16]. While a cross-words variation modelling has been done in many Languages, little work in Arabic is done. Two well-known MSA phonological rules are applied, assimilation (Idgham) and changing (Iqlaab).

There are 3 types of assimilation

- Noon Saakinah or Tanween 


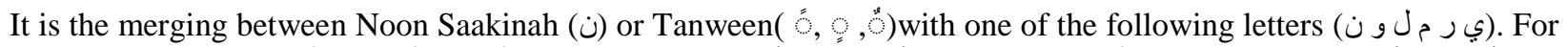

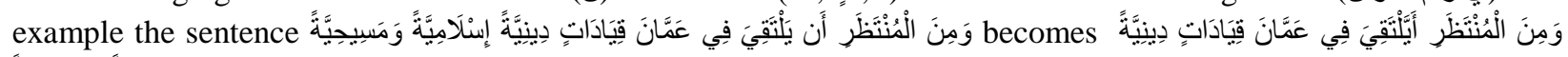
إِنْلَامِيَّةً وَمَبِيحِيَّةً

- Assimilation of identical letters

An unvoweled consonant on the end of a word is merged with a same voweled consonant at the beginning of the

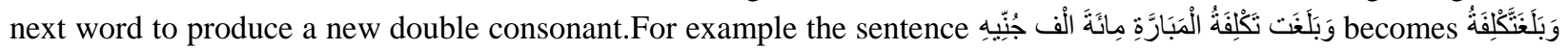

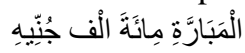

- Assimilation of two close in pronunciation letters

Two successive different letters that are close in pronunciation as indicated in table 3 are merged and becoming one

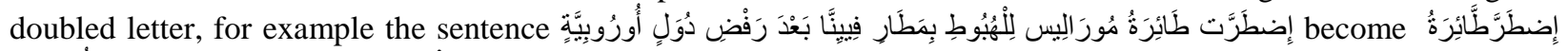

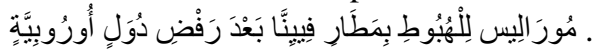

Table 3 Idgham of two close in pronunciation letters

\begin{tabular}{|c|c|c|}
\hline $\begin{array}{l}\text { Last letter Of first word } \\
\text { Unvowelled }\end{array}$ & $\begin{array}{l}\text { First letter of second word } \\
\text { Vowelled }\end{array}$ & $\begin{array}{l}\text { Connecting letter } \\
\text { Double }\end{array}$ \\
\hline TEH (ت) & DAL(د) & DAL(د) \\
\hline $\mathrm{THE}(ت)$ & TAH(b) & TAH(b) \\
\hline DAL(د) & $\mathrm{THE}(ت)$ & THE $(ت)$ \\
\hline BA(ب) & $\operatorname{MEM}($ () & $\operatorname{MEM}($ () \\
\hline DH ( & DH2(ظ) & DH2(ظ) \\
\hline $\mathrm{KAF}(5)$ & QAF(ق) & QAF(ق) \\
\hline $\operatorname{LAM}(\mathrm{J})$ & $\operatorname{RA}(\jmath)$ & $\operatorname{RA}(\jmath)$ \\
\hline THA(ث) & THAL(ذ) & THAL(ذ) \\
\hline TAH(b) & THE(ت) & THE(ت) \\
\hline
\end{tabular}

The Iqlaab is a replacement of Noon Saakinah (ن) or Tanween ( Meem Saakinah (م ). for example the sentence وَنَصَحَتِ

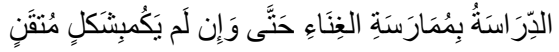

Handling tanween is different not only removing tanween $\operatorname{sign}(\dot{8})$ from the letter but also adding a vowel

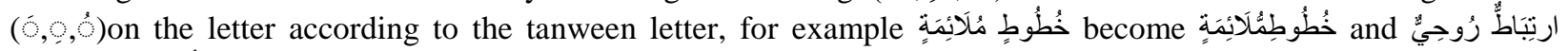

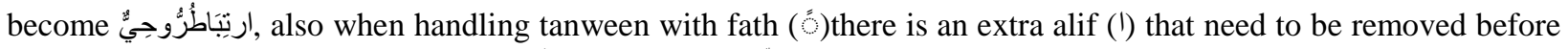

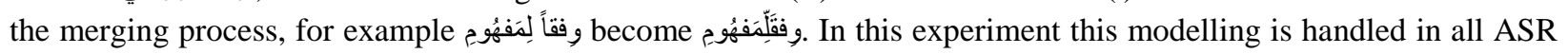
component the dictionary acoustic model and the language model. First phonetic adaption is done followed by adapting language and the adapted model used in training acoustic model to generate model parameter. The proposed model outperforms the base line with error rate $10.47 \%$ and the execution time is the same as the base system execution time as showed in table 4,where I:Word Insertion errors; D: word deletion errors; S: word substitution errors; WER: \% word error rate, based on 1251word in 100 sentence test corpus. 
Table 4 the performance of the ASR system for different test cases

\begin{tabular}{|l|l|l|l|l|l|l|}
\hline \multicolumn{2}{|l|}{ Test case } & WER \% & I & D & S & $\begin{array}{l}\text { Execution } \\
\text { time in } \\
\text { seconds }\end{array}$ \\
\hline \multicolumn{2}{|l|}{ Base system } & 11.27 & $\mathbf{3 1}$ & $\mathbf{4}$ & $\mathbf{1 0 6}$ & $\mathbf{3 0 . 3}$ \\
\hline \multirow{2}{*}{$\begin{array}{l}\text { Within } \\
\text { word } \\
\text { variation }\end{array}$} & \begin{tabular}{l} 
Noon \\
assimilation \\
\cline { 2 - 7 } \\
noon assimilation
\end{tabular} & 11.43 & $\mathbf{3 0}$ & $\mathbf{3}$ & $\mathbf{1 1 0}$ & $\mathbf{3 0 . 3}$ \\
\hline \multicolumn{2}{|l|}{\begin{tabular}{l} 
Cross word variation \\
\hline
\end{tabular}} & 10.47 & $\mathbf{3 1}$ & $\mathbf{2}$ & $\mathbf{1 1 0}$ & $\mathbf{4 0 . 4}$ \\
\hline
\end{tabular}

\section{Conclusion}

Handling Arabic pronunciations variation influence Arabic ASR systems performance. Two types of variation exist which are within-word variations and cross- word variations. Handling within-word variation (Noon assimilation and shadda) using phonological rules (the knowledge-based approach) has no significant effect on system performance. On the other hand, better performance is achieved when handling cross-word variation by phonological rules. Accordingly, handling within-word variation using data driven approach need to be examined. Also more phonological rules to handle other cross-word variation will be checked.

\section{REFERENCES}

[1] Elmahdy et al. used acoustic models trained with large MSA news broadcast speech corpus to work as multilingual or multiaccent models to decode colloquial Arabic(2009).

[2] Al-Anzi Fawaz S, AbuZeina Dia, "The impact of phonological rules on Arabic speech recognition", International Journal of Speech Technology, vol. 20, no. 3, pp. 715-723, 2017.

[3] Abed, S., Alshayeji, M. and Sultan, S. 2019. Diacritics Effect on Arabic Speech Recognition. Arabian Journal for Science and Engineering. (2019).

[4] Abuzeina, D., Al-Khatib, W., Elshafei, M., Al-Muhtaseb, H., 2011. Cross-word Arabic pronunciation variation modeling for speech recognition.Int. J. Speech Technol. 14 (3), 227-236.

[5] Fosler-Lussier, E., Greenberg, S., Morgan, N., et al., 1999. Incorporating contextual phonetics into automatic speech recognition. Nucleus 48993(65.3), 62118.

[6] Ramsay, A., Alsharhan, I., Ahmed H. (2014). Generation of a phonetic transcription for modern standard Arabic: A knowledge based model. Computer Speech \& Language, 28(4), 959-978.

[7] Amdal, I., Fosler-Lussier, E., 2003. Pronunciation variation modeling in automatic speech recognition. Telektronikk 99 (2), $70-82$.

[8]Wester, M., Fosler-Lussier, E., 2000. A comparison of data-derived and knowledge-based modeling of pronunciation variation. 
[9] Helmer, S. (2001). Pronunciation adaptation at the lexical level. In Proceedings ISCA ITRW workshop adaptation methods for speech recognition, Sophia Antipolis, France.

[10] Ali, M., Moustafa, E., Mansour, A., Husni, A., \& Atef, A. (2009). Arabic phonetic dictionaries for speech recognition. Journal of Information Technology Research, 2(4), 67-80.

[11] Algamdi, M., Almuhtasib, H., \& Elshafei, M. (2004).Arabic Phonological Rules. [King Saud University.].Journal of Computer Sciences and Information, 16, 1-25.

[12] Elshafei-Ahmed, M. (1991). Toward an Arabic Text-to-Speech System. The Arabian Journal of Scienceand Engineering, 16(4B), 565-583.

[13] Billa et al. (2002). Arabic speech and test in tides on tap. In Proceedings of HLT.

[14] Alghamdi, M., Elshafei, M., \& Almuhtasib, H. (2009). Arabic broadcast news transcription system. International Journal of Speech and Technology, 10, 183-195.

[15 ] Masmoudi, A., et al. (2014) A Corpus and Phonetic Dictionary for Tunisian Arabic Speech Recognition. In LREC.

[16] Al-Haj, H., Hsiao, R., Lane, I., Black, W. A., \& Waibel, A. (2009).Pronunciation modeling for dialectal Arabic speech recognition.In ASRU 2009: IEEE workshop, Italy. 